\title{
Bite wound related infections in rural areas of Macedonia-Greece: consequences on overall health
}

\author{
Nikolaos Syrmos*, Andreas Televantos, Stefanos Patiakas, Nikolaos Kapoutzis \\ From $1^{\text {st }}$ International Congress on Neurobiology and Clinical Psychopharmacology and European \\ Psychiatric Association Conference on Treatment Guidance \\ Thessaloniki, Greece. 19-22 November 2009
}

\section{Background}

In this 20 year retrospective study (1989-2009) depicted injuries recorded as dog, cat, horse and human bites from one hospital(Goumenissa General Hospital, Kilkis, Macedonia, Greece).

\section{Materials and methods}

The injuries were 35 dog bite, 5 cat bite, 5 horse bite, 4 human bite.The incidence was higher in aged people (over 65 yerars old) and in children, dominant in males and were higher in summer. The highest humidity and highest temperatures was determined for dog-bites.

\section{Results}

In all the cases with the routine therapy (antitetanus vaxine, local debridement, Antibiotics) we achieved good results

\section{Conclusions}

Bite infections can contain a mix of anaerobes and aerobes from the patient's skin and the animal's oral cavity, including species of Pasteurella, Streptococcus, Fusobacterium, and Capnocytophaga. The most common pathogens associated with bite wounds are Streptococcus species, Staphylococcus species, Pasteurella multocida, Capnocytophaga canimorsus and anaerobic bacteria. Sporadically other pathogens are isolated from bite wounds. Human bites differ from animal bites by higher prevalence of Staphylococcus aureus and Eikenella corrodens. The lifetime risk of experiencing a bite wound, human or animal, is approximately $40 \%$, and bite wounds account for approximately $2 \%$ of all visits to emergency departments. The majority of bite wounds are inflicted by dogs. It is important to be aware of the possibility of complicating infections following bite wounds, particularly after cat bites. Phenoxymethyl penicillin should be the drug of choice in treatment of infections associated with cat and dog bites. However, in case of slow recovery or no improvement, simultaneous lymphadenopathy or pneumonia, S. aureus or Francisella tularensis should be suspected; ciprofloxacin is recommended. For human bite infections the recommend treatment is phenoxymethyl penicillin in combination with penicillinase-stable penicillin.

Published: 22 April 2010

\section{References}

1. Yaqub S, Bjørnholt JV, Hellum KB, Steinbakk M, Enger AE: Bite wound infections Tidsskr Nor Laegeforen. 2004, 124(24):3194-6.

2. Emet M, Beyhun N, Kosan Z, Aslan S, Uzkeser M, Cakir Z: Animal-related injuries: epidemiological and meteorological features. Ann Agric Environ Med 2009, 16(1):87-92

3. Oehler RL, Velez AP, Mizrachi M, Lamarche J, Gompf S: Bite-related and septic syndromes caused by cats and dogs. Lancet Infect Dis 2009, 9(7):439-47, Review. Griego RD, Rosen T, Orengo IF, Wolf JE.Dog, cat, and human bites: a review. J Am Acad Dermatol. 1995 Dec;33(6):1019-29.

doi:10.1186/1744-859X-9-S1-S97

Cite this article as: Syrmos et al: Bite wound related infections in rural areas of Macedonia-Greece: consequences on overall health. Annals of General Psychiatry 2010 9(Suppl 1):S97.

Surgical Department, Goumenissa General Hospital, Kilkis, Macedonia, Greece 